\title{
ANALISIS KEBUTUHAN TENAGA KESEHATAN (PARAMEDIS) BERDASARKAN BEBAN KERJA DENGAN MENGGUNAKAN METODE WORKLOAD INDICATOR STAFFING NEEDS (WISN) DI POLIKLINIK ASS-SYIFAH UIN ALAUDDIN
}

\author{
Syamsul Alam ${ }^{1}$, Sitti Raodhah ${ }^{2}$, Surahmawati ${ }^{3}$ \\ 1, Bagian Gizi Universitas Islam Negeri Alauddin Makassar \\ ${ }^{2,3}$ Bagian Administrasi Kebijakan Kesehatan Universitas Islam Negeri Alauddin Makassar
}

\begin{abstract}
ABSTRAK
Analisis beban kerja merupakan upaya menghitung beban kerja pada satuan kerja dengan cara menjumlah semua beban kerja dan selanjutnya membagi dengan kapasitas kerja perorangan persatuan waktu. Penelitian bertujuan untuk mengetahui kebutuhan tenaga kesehatan (paramedis) dengan menghitung perbedaan antara jumlah ideal tenaga paramedis (tenaga perawat dan tenaga farmasi) dengan kenyataan yang ada (WISN difference) serta menghitung beban kerja pada Unit Poliklinik Ass Syifaa UIN Alauddin Makassar. Jenis penelitian ini adalah deskriptifdengan metode kuantitatif dan kualitatif secara bersamaan untuk menganalisa beban kerja dan memperoleh jumlah tenaga paramedis yakni tenaga kepearawatan dan kefarmasian berdasarkan metode Workload Indicator Staffing Need (WISN). Sumber data kuantitatif adalah tenaga keperawatan dan kefarmasian yang bekerja di Poliklinik Ass-Syifaa UIN Alauddin dan Informan sebagai sumber data kualitatif yang dipilih oleh peneliti yaitu manajemen poliklinik yang berkaitan dengan pelayanan keperawatan dan kefarmasian. Hasil analisis kebutuhan tenaga paramedis berdasarkan beban kerja petugas dengan menggunakan metode WISN pada Poliklinik Ass-Syifah UIN Alauddin Makassar diperoleh tenaga perawat sebanyak 0,695 SDM atau jika dibulatkan menjadi 1 SDM. Sedangkan jumlah kebutuhan tenaga farmasi yang ideal adalah sebesar 3,38 SDM atau 4 SDM. Penggunaan metode WISN ini untuk memudahkan dalam pemenuhan dan distribusi dari tenaga kesehatan terutama di poliklinik sehingga diharapkan hasil penelitian dapat dimanfaatkan sebagai sumber masukan bagi pimpinan mengevaluasi kebutuhan SDM
\end{abstract}

Kata Kunci : Tenaga Kesehatan, SDM, WISN, Poliklinik

\section{PENDAHULUAN}

Pengembangan sumber daya manusia (SDM) membutuhkan biaya investasi dan merupakan asset, karena SDM merupakan penghasil pendapatan pada Fasilitas Pelayanan Kesehatan. Pemenuhan kebutuhan SDM merupakan suatu hal krusial bagi pengelola SDM perusahaan. Pengelola SDM harus mampu menghitung kebutuhan SDM secara tepat berdasarkan kebutuhan unit pelayanan. Kelebihan pemenuhan kebutuhan SDM memberikan konsekuensi biaya tenaga kerja yang tinggi dan menimbulkan ketidakefisienan dalam pengelolaan 
keuangan. Kekurangan pemenuhan kebutuhan SDM memberikan efek beban kerja yang tinggi kepada tenaga kerja dan berakibat menurunkan kepuasan dalam bekerja, meningkatkan kejadian burnout, mening- kerja dengan cara menjumlah semua beban kerja dan selanjutnya membagi dengan kapasitas kerja perorangan persatuan waktu. Kepmenkes RI No. 81/Menkes/SK/I/2004 tentang Pedoman Penyusunan Perencanaan

Tabel 1. Standar Beban Kerja Tenga Keperawatan dan Kefarmasian

\begin{tabular}{|c|c|c|c|c|c|c|}
\hline \multirow{2}{*}{ No } & \multirow{2}{*}{ Uraian Tugas Keperawatan } & \multirow{2}{*}{$\begin{array}{c}\text { Rata-rata Waktu } \\
\text { per Kegiatan }\end{array}$} & \multicolumn{4}{|c|}{ STANDAR BEBAN KERJA } \\
\hline & & & $\mathrm{R} 1$ & $\mathrm{R} 2$ & R3 & $\mathrm{R} 4$ \\
\hline 1 & Melakukan anamnesi pasien & 5 & 16920 & 16992 & 16848 & 16848 \\
\hline 2 & Melakukan pemeriksaan fisik & 5 & 16920 & 16992 & 16848 & 16848 \\
\hline 3 & Melakukan pemeriksaan kimia darah sesuai permintaan pasien & 10 & 8460 & 8496 & 8424 & 8424 \\
\hline 4 & Melakukan tensi tekanan darah & 5 & 16920 & 16992 & 16848 & 16848 \\
\hline 5 & Pemeriksaan berbadan sehat & 10 & 8460 & 8496 & 8424 & 8424 \\
\hline 6 & Pelayanan ugd & 120 & 705 & 708 & 702 & 702 \\
\hline 7 & Melakukan tindakan suntuk KB & 10 & 8460 & 8496 & 8424 & 8424 \\
\hline 8 & Melakukan cabut gigi & 30 & 2820 & 2832 & 2808 & 2808 \\
\hline 9 & Perawatan karang gigi & 60 & 1410 & 1416 & 1404 & 1404 \\
\hline 10 & Pemasangan Ekg & 30 & 2820 & 2832 & 2808 & 2808 \\
\hline No & Uraian Tugas Kefarmasian & $\begin{array}{c}\text { Rata-rata Waktu } \\
\text { per Kegiatan }\end{array}$ & \multicolumn{4}{|c|}{ SBK } \\
\hline 1 & Pelayanan informasi obat & 15 & \multicolumn{2}{|c|}{5712} & \multicolumn{2}{|c|}{5688} \\
\hline 2 & Pemeriksaan lab & 40 & \multicolumn{2}{|c|}{2142} & \multicolumn{2}{|c|}{2133} \\
\hline 3 & Pembuatan laporan alur masuk obat & 360 & \multicolumn{2}{|c|}{238} & \multicolumn{2}{|c|}{237} \\
\hline 4 & Pemeriksaan stok obat & 240 & \multicolumn{2}{|c|}{357} & \multicolumn{2}{|c|}{355,5} \\
\hline 5 & Pendataan obat ulang & 60 & \multicolumn{2}{|c|}{238} & \multicolumn{2}{|c|}{1422} \\
\hline 6 & Pengadaan obat & 30 & \multicolumn{2}{|c|}{2857} & \multicolumn{2}{|c|}{2844} \\
\hline 7 & Penyimpanan obat & 90 & \multicolumn{2}{|c|}{952} & \multicolumn{2}{|c|}{948} \\
\hline 8 & Pencatatan pembelian obat & 60 & \multicolumn{2}{|c|}{1428} & \multicolumn{2}{|c|}{1422} \\
\hline 9 & Pelayanan UGD & 180 & \multicolumn{2}{|c|}{476} & \multicolumn{2}{|c|}{474} \\
\hline 10 & Pelayanan rawat jalan & 40 & \multicolumn{2}{|c|}{2142} & \multicolumn{2}{|c|}{2133} \\
\hline 11 & Pengadaan strip lab & 240 & \multicolumn{2}{|c|}{357} & \multicolumn{2}{|c|}{355,5} \\
\hline 12 & Pelaporan pemeriksaan lab & 360 & \multicolumn{2}{|c|}{238} & \multicolumn{2}{|c|}{237} \\
\hline 13 & Peracikan obat & 45 & \multicolumn{2}{|c|}{1904} & \multicolumn{2}{|c|}{1896} \\
\hline
\end{tabular}

Sumber :Data Primer, 2018

katkan keinginan pindah kerja, menurunkan kualitas keselamatan pasien dan akhirnya akan menurunkan kualitas pelayanan kepada pasien.

Analisis beban kerja merupakan upaya menghitung beban kerja pada satuan
Sumber Daya Manusia Kesehatan Di Tingkat Propinsi, Kabupaten/Kota serta rumah sakit merupakan pedoman yang digunakan untuk penyusunan rencana penyediaan dan kebutuhan SDM di institusi pelayanan kesehatan. Pedoman tersebut menggunakan 
metode WISN (Workload Indicators of Staffing Need), metode tersebut merupakan indikator yang menunjukkan besarnya kebutuhan tenaga pada sarana kesehatan berdasarkan beban kerja, sehingga lokasi/relokasi akan lebih mudah dan rasional.

Polikllink UIN Alauddin merupakan fasilitas kesehatan yang berada di dalam Lingkungan Kampus II UIN Alauddin yang menyelenggarakan pelayanan kesehatan kepada civitas akademika. Secara keseluruhan jumlah tenaga medis dan paramedis yang memberikan pelayanan kesehatan di Poliklinik UIN Alauddin sejumlah 9 orang terdiri dari 2 dokter umum, 2 dokter gigi, 4 perawat, 1 Apoteker dan 1 asisten apoteker. Jumlah tenaga medis dan paramedis tersebut seharusnya sudah sesuai apabila dibandingkan dengan standar minimal ketenagaan di perkotaan menurut Peraturan Menteri Kesehatan RI Nomor 75 Tahun 2014 tentang institrusi pelayanan kesehatan, bahkan untuk kategori dokter gigi sudah melebihi standar yang minimalnya berjumlah 1 orang.

Pelayanankesehatan melalui Unit Poliklkinik Asy Syifaa UIN Alauddin memberikan kontribusi cukup besar di dalam mewujudkan universitas yang berperadaban dan civitas akademika yang sehat serta produktif. Keberhasilan pelayanan kesehatan didukung oleh sumber daya manusia yang mumpuni. Untuk mencapai visi dan misi poliklkinik, keterampilan dan kemampuan sumber daya manusia sangat diperlukan untuk mendiagnosa dan mengintervensi permasalahan sehingga didapatkan penyelesaian dari setiap permasalahan yang menjadi tugas dan fungsi unit layanan kesehatan kampus.

Dari hasil pengamatan di Poliklinik UIN Alauddin, perencanaan kebutuhan tenaga kesehatan yang dibuat masih belum sempurna. Dilihat dari segi alur proses kebijakan perencanaan kebutuhan tenaga belum terstruktur dengan baik. Perencanaan kebutuhan tenaga kesehatan selama ini masih bersifat administratif kepegawaian di Bagian Kepegawaian Rektorat UIN Alauddin dan belum dikelola secara professional berdasarkan beban kerja dengan kebutuhan SDM pada Unit Poliklinik. Akibatnya, jumlah tenaga yang ada belum sesuai dengan beban kerja dan kebutuhan nyata di lapangan. Untuk mengetahui kebutuhan akan tenaga paramedis pada Poliklinik UIN Alauddin dengan melalui proses administrasi tanpa melalui proses perhitungan kebutuhan tenaga kesehatan berdasarkan Kepmenpan atau pun WISN. Berdasarkan latar belakang yang diuraikan, penulis tertarik untuk melakukan analisis kebutuhan tenaga paramedis menggunakan metode Workload Indicator Staffing Needs (WISN) di Poliklinik Ass Syifah UIN Al- 
auddin Makassar

Penelitian bertujuan untuk mengetahuikebutuhan tenaga kesehatan (paramedis) dengan menghitung perbedaan antara jumlah ideal tenaga paramedis (tenaga perawat dan tenaga farmasi) dengan kenyataan yang ada (WISN difference) serta menghi- medis yakni tenaga kepearawatan dan kefarmasian berdasarkan metode Workload Indicator Staffing Need (WISN). Sumber data kuantitatif adalah tenaga keperawatan dan kefarmasian yang bekerja di Poliklinik Ass-Syifaa UIN Alauddin dan Informan sebagai sumber data kualitatif yang dipilih

Tabel 2. Standar Kelonggaran Tenaga Keperawatan

\begin{tabular}{|c|c|c|c|c|c|c|c|c|c|c|c|c|c|c|c|c|c|}
\hline \multirow{2}{*}{ No } & \multirow{2}{*}{ Kegiatan } & \multicolumn{4}{|c|}{$\begin{array}{c}\text { Kuantitas } \\
\text { (PerThn) }\end{array}$} & \multicolumn{4}{|c|}{$\begin{array}{c}\text { Waktu } \\
\text { (Jam/Keg) }\end{array}$} & \multicolumn{4}{|c|}{$\begin{array}{c}\text { Waktu Kerja } \\
\text { Tersedia (Jam/thn) }\end{array}$} & \multicolumn{4}{|c|}{ Standar Kelonggaran } \\
\hline & & $\mathbf{R} 1$ & $\mathbf{R 2}$ & R3 & R4 & R1 & $\mathbf{R 2}$ & R3 & $\mathbf{R} 4$ & $\mathbf{R} 1$ & $\mathbf{R 2}$ & $\mathbf{R 3}$ & R4 & R1 & $\mathbf{R 2}$ & $\mathbf{R 3}$ & R4 \\
\hline 1 & Rapat kerja kordinasi & 2 & 2 & 2 & 2 & 2 & 2 & 2 & 2 & 1410 & 1416 & 1404 & 1404 & 0,003 & 0,003 & 0,003 & 0,003 \\
\hline 2 & $\begin{array}{l}\text { Menyusun rencana jobdesk } \\
\text { bualanan }\end{array}$ & 12 & 12 & 12 & 12 & 1 & 1 & 1 & 1 & 1410 & 1416 & 1404 & 1404 & 0,009 & 0,008 & 0,009 & 0,009 \\
\hline 3 & mengawas ujian tes masuk & 1 & 1 & 1 & 1 & 4 & 4 & 4 & 4 & 1410 & 1416 & 1404 & 1404 & 0,003 & 0,003 & 0,003 & 0,003 \\
\hline \multirow[t]{2}{*}{4} & $\begin{array}{l}\text { Rekab pemeriksaan } \\
\text { kesehatan mahasiswa baru }\end{array}$ & 0 & 0 & 0 & 52 & 0 & 0 & 0 & 1 & 0 & 0 & 0 & 1404 & 0 & 0 & 0 & 0,037 \\
\hline & \multicolumn{13}{|c|}{ JUMLAH } & 0,014 & 0,014 & 0,014 & 0,051 \\
\hline
\end{tabular}

Sumber :Data Primer, 2018

tung beban kerja pada Unit Poliklinik Ass Syifaa UIN Alauddin Makassar.

\section{METODE PENELITIAN}

Penelitian ini dilakukan di Poliklinik UIN Alauddin pada bulan september sampai dengan november tahun 2018, Objek dalam penelitian ini adalah beban kerja tenaga keperawatan dan tenaga farmasi (paramedis) di Poliklinik UIN Alauddin.

Jenis penelitian ini adalah deskriptifdengan metode kuantitatif dan kualitatif secara bersamaan untuk menganalisa beban kerja dan memperoleh jumlah tenaga para- oleh peneliti yaitu manajemen poliklinik yang berkaitan dengan pelayanan keperawatan dan kefarmasian.

Sampel penelitian adalah seluruh tenaga keperawatan sebanyak 4 orang dan kefarmasian sebanyak 2 orang yang bekerja di Poliklinik Ass-Syifaa UIN Alauddin. Pengumpulan data primer dilakukan dengan pengamatan langsung terhadap kegiatan yang dilakukan oleh tenaga keperawaratan dan kefarmasian selama jam kerja, wawancara dengan beberapa informan dan data sekunder yang diperoleh dari data yang berasal dari data bagian SDM Poliklinik, 
laporan pelayanan pasien tahun 2017 dan laporan kinerja tenaga paramedis pada eLKP (elektronik Lembar Kerja Pegawai) UIN Alauddin Makassar. Dari data-data tersebut lalu dimasukkan ke dalam rumus kedinasan sesuai dengan aturan

Poliklinik dan UIN Alauddin

$\mathrm{D}=$ Hari Libur Nasional

$\mathrm{E}=$ Ketidakhadiran Kerja karena sakit, izin dan lain sebagainya.

$\mathrm{F}=$ Waktu kerja dalam satu hari

\section{Tabel 3. Standar Kelonggaran Tenaga Kefarmasian}

\begin{tabular}{lccccccccc}
\hline & \multicolumn{1}{c}{ Kegiatan } & $\begin{array}{c}\text { Kuantitas } \\
\text { (PerThn) }\end{array}$ & $\begin{array}{c}\text { Waktu } \\
\text { (Jam/Keg) }\end{array}$ & $\begin{array}{c}\text { Waktu Kerja } \\
\text { Tersedia } \\
\text { (Jam/thn) }\end{array}$ & $\begin{array}{c}\text { Standar } \\
\text { Kelonggaran }\end{array}$ \\
\cline { 2 - 9 } & R5 & $\mathbf{R 6}$ & $\mathbf{R 5}$ & $\mathbf{R 6}$ & $\mathbf{R 5}$ & $\mathbf{R 6}$ & $\mathbf{R 5}$ & $\mathbf{R 6}$ \\
\hline 1 Rapat kerja koordinasi & 3 & 3 & 3 & 3 & 1428 & 1422 & 0,006 & 0,006 \\
2 Pengurusan permintaan strip narkoba & 1 & 1 & 2 & 2 & 1428 & 1422 & 0,001 & 0,001 \\
3 & Rekap pemeriksaan Maba (Lab) & 60 & 60 & 1 & 1 & 1428 & 1422 & 0,042 & 0,042 \\
4 & Tim medis kegiatan kampus & 6 & 6 & 6 & 6 & 1428 & 1422 & 0,025 & 0,025 \\
5 & Menyusun rencana jobdesk bualanan & 12 & 12 & 1 & 1 & 1428 & 1422 & 0,008 & 0,008 \\
6 mengawas ujian tes masuk & 1 & 1 & 4 & 4 & 1428 & 1422 & 0,003 & 0,003 \\
\hline
\end{tabular}

Sumber :Data Primer, 2018

perhitungan jumlah tenaga dari Workload Indicators of Staffing Need (WISN). langkah perhitungan kebutuhan tenaga berdasarkan WISN meliputi langkahlangkah :

1) Menetapkan waktu kerja tersedia, dengan rumus:

Waktu kerja tersedia $=(\mathrm{A}-(\mathrm{B}+\mathrm{C}+\mathrm{D}+\mathrm{E})) \mathrm{x} \mathrm{F}$, dimana :

$\mathrm{A}=$ Hari kerja yang mungkin dalam setahun

$\mathrm{B}=$ Cuti tahunan

$\mathrm{C}=$ Pendidikan, Pelatihan dan tugas
2) Menetapkan unit kerja dan kategori SDM

3) Menyusun standar beban kerja.

Standar beban kerja diperoleh dengan membagi waktu kerja tersedia dalam satu tahun dengan ratarata waktu penyelesaian setiap unit kegiatan pokok. Waktu penyelesaian setiap unit kegiatan pokok adalah rata-rata jumlah waktu setiap kegiatan pokok dalam 1 hari dibagi dengan rata-rata jumlah kegiatan pokok dalam satu hari kerja. 
4) Menyusun standar kelonggaran. faktor yang digunakan untuk menghitung kebutuhan tenaga paramedis dalam melaksanakan kegiatan yang secara rutin tidak dicatat dalam statistik tahunan yaitu aktivitas penunjang dan aktivitas tambahan. tode Workload Indicator Staff Need (WISN) diperoleh:

\section{Waktu Kerja Tersedia Tenaga Medis}

Jumlah hari kerja bagi tenaga paramedis adalah 5 hari per minggu atau 259 hari dalam 1 tahun di 2017. Hari libur nasional

\section{Tabel 4. Kebutuhan Tenaga Perawat Berdasarkan Hasil Analisis Kebutuhan SDM}

\begin{tabular}{|c|c|c|c|c|c|c|c|c|c|c|c|c|c|}
\hline \multirow{2}{*}{ No } & \multirow{2}{*}{ Kegiatan } & \multicolumn{4}{|c|}{ SBK } & \multicolumn{4}{|c|}{ Kuantitas (Kali/thn) } & \multicolumn{4}{|c|}{ Kebutuhan SDM } \\
\hline & & $\mathrm{R} 1$ & $\mathrm{R} 2$ & $\mathrm{R} 3$ & $\mathrm{R} 4$ & R1 & $\mathrm{R} 2$ & R3 & $\mathrm{R} 4$ & $\mathrm{R} 1$ & $\mathrm{R} 2$ & R3 & $\mathrm{R} 4$ \\
\hline 1 & Melakukan anamnesi pasien & 16920 & 16992 & 16848 & 16848 & 133 & 133 & 130 & 140 & 0,0079 & 0,0078 & 0,0077 & 0,0083 \\
\hline 2 & Melakukan pemeriksaan fisik & 16920 & 16992 & 16848 & 16848 & 1325 & 1320 & 1340 & 1360 & 0,0783 & 0,0777 & 0,0795 & 0,0807 \\
\hline 3 & $\begin{array}{l}\text { Melakukan pemeriksaan kimia darah sesuai } \\
\text { permintaan pasien }\end{array}$ & 8460 & 8496 & 8424 & 8424 & 10 & 10 & 10 & 10 & 0,0012 & 0,0012 & 0,0012 & 0,0012 \\
\hline 4 & Melakukan tensi tekanan darah & 16920 & 16992 & 16848 & 16848 & 10 & 10 & 12 & 12 & 0,0006 & 0,0006 & 0,0007 & 0,0007 \\
\hline 5 & Pemeriksaan berbadan sehat & 8460 & 8496 & 8424 & 8424 & 240 & 215 & 260 & 235 & 0,0284 & 0,0253 & 0,0309 & 0,0279 \\
\hline 6 & Pelayanan ugd & 705 & 708 & 702 & 702 & 24 & 26 & 25 & 22 & 0,034 & 0,0367 & 0,0356 & 0,0313 \\
\hline 7 & Melakukan tindakan suntuk KB & 8460 & 8496 & 8424 & 8424 & 2 & 2 & 1 & 1 & 0,0002 & 0,0002 & 0,0001 & 0,0001 \\
\hline 8 & Melakukan cabut gigi & 2820 & 2832 & 2808 & 2808 & 0 & 0 & 0 & 0 & 0 & 0 & 0,0000 & 0,0000 \\
\hline 9 & Perawatan karang gigi & 1410 & 1416 & 1404 & 1404 & 0 & 0 & 0 & 0 & 0 & 0 & 0,0000 & 0,0000 \\
\hline 10 & Pemasangan Ekg & 2820 & 2832 & 2808 & 2808 & 2 & 1 & 2 & 1 & 0,0007 & 0,0004 & 0,0007 & 0,0004 \\
\hline \multicolumn{10}{|c|}{ Jumlah } & 0,1513 & 0,1499 & 0,1565 & 0,1506 \\
\hline \multicolumn{10}{|c|}{ Standar Kelonggaran } & 0,0142 & 0,0141 & 0,0142 & 0,0513 \\
\hline \multicolumn{10}{|c|}{ Jumlah Kebutuhan SDM } & 0,1655 & 0,164 & 0,1707 & 0,2019 \\
\hline \multicolumn{10}{|c|}{ Jumlah Kebutuhan SDM Tenaga Perawat ( R1 + R2 + R3 + R5 ) } & \multicolumn{4}{|c|}{0,695 atau $1 \mathrm{SDM}$} \\
\hline
\end{tabular}

Sumber :Data Primer, 2018

5) Perhitungan kebutuhan tenaga dengan rumus

$\mathrm{SDM}=\left[\frac{\text { Kuantitas Kegiatan Pokok }}{\text { Standar Beban Kerja }}\right]+$ Standar Kelonggaran

\section{HASIL PENELITIAN}

Hasil analisis perhitungan kebutuhan tenaga paramedis (tenaga keparawatan dan kefarmasian) pada Poliklinik Ass-Syifaa UIN Alauddin dengan menggunakan me- berdasarkan Keputusan Bersama Menteri terkait tentang Libur Nasional dan Cuti Bersama tahun 2017 ditetapkan 16 hari dan 3 hari untuk cuti bersama. Jumlah ketidakhadiran kerja dengan alasan sakit dan tidak masuk kerja dengan alasan lain dihitung dari total jumlah ketidakhadiran selama 1 tahun. Waktu kerja efektif bagi tenaga paramedis di poliklinik adalah 6 jam/hari, Hasil olah data menunjukkan waktu kerja tersedia 
yang dimiliki oleh tenaga paramedis di polikklinik UIN Alauddin Makassar berbeda setiap petugas. Salah factor yang mempengaruhi adanya perbedaan waktu kerja yang tersedia adalah ketidakhadiran kerja pada hari kerja yang berbeda pada setiap petugas. kerja tersedia dalam 1 tahun. Sedangkan kegiatan yang memiliki standar beban kerja yang tinggi adalah adalah melakukan anamnesis pasien, melakukan pemeriksaan fisik, melakukan pemeriksaan tekanan darah yakni sebesar 16.848 menit/tahun/ petugas, hal ini menunjukkan melakukan

Tabel 5. Kebutuhan Tenaga Farmasi Berdasarkan Hasil Analisis Kebutuhan SDM

\begin{tabular}{|c|c|c|c|c|c|c|c|}
\hline \multirow{2}{*}{ No } & \multirow{2}{*}{ Kegiatan } & \multicolumn{2}{|c|}{ SBK } & \multirow{2}{*}{$\begin{array}{c}\begin{array}{c}\text { Kuantitas } \\
\text { (Kali/thn) }\end{array} \\
\text { R5 }\end{array}$} & \multicolumn{3}{|c|}{ Kebutuhan SDM } \\
\hline & & R5 & R6 & & R6 & R5 & R6 \\
\hline 1 & Pelayanan informasi obat & 5712 & 5688 & 274 & 260 & 0,0480 & 0,0457 \\
\hline 2 & Pemeriksaan lab & 2142 & 2133 & 2866 & 2804 & 1,3380 & 1,3146 \\
\hline 3 & Pembuatan laporan alur masuk obat & 238 & 237 & 8 & 5 & 0,0336 & 0,0211 \\
\hline 4 & Pemeriksaan stok obat & 357 & 355,5 & 3 & 3 & 0,0084 & 0,0084 \\
\hline 5 & Pendataan obat ulang & 238 & 1422 & 8 & 4 & 0,0336 & 0,0028 \\
\hline 6 & Pengadaan obat & 2857 & 2844 & 4 & 2 & 0,0014 & 0,0007 \\
\hline 7 & Penyimpanan obat & 952 & 948 & 3 & 3 & 0,0032 & 0,0032 \\
\hline 8 & Pencatatan pembelian obat & 1428 & 1422 & 3 & 3 & 0,0021 & 0,0021 \\
\hline 9 & Pelayanan UGD & 476 & 474 & 34 & 28 & 0,0714 & 0,0591 \\
\hline 10 & Pelayanan rawat jalan & 2142 & 2133 & 162 & 150 & 0,0756 & 0,0703 \\
\hline 11 & Pengadaan strip lab & 357 & 355,5 & 1 & 1 & 0,0028 & 0,0028 \\
\hline 12 & Pelaporan pemeriksaan lab & 238 & 237 & 7 & 7 & 0,0294 & 0,0295 \\
\hline 13 & Peracikan obat & 1904 & 1896 & 6 & 9 & 0,0032 & 0,0047 \\
\hline \multicolumn{6}{|c|}{ Jumlah } & 1,6507 & 1,5651 \\
\hline \multicolumn{6}{|c|}{ Standar Kelonggaran } & 0,086 & 0,083 \\
\hline \multicolumn{6}{|c|}{ Jumlah Kebutuhan SDM } & 1,7367 & 1,6481 \\
\hline \multicolumn{6}{|c|}{ Jumlah Kebutuhan SDM Tenaga Perawat ( R1 + R2 + R3 + R5 ) } & \multicolumn{2}{|c|}{3,38 atau 4 SDM } \\
\hline
\end{tabular}

Sumber :Data Primer, 2018

\section{Standar Beban Kerja}

Berdasarkan perhitungan beban kerja (tabel 1) pada tenaga perawat beban kerja paling rendah adalah pelayanan unit gawat darurat yakni sebesar 702-708 menit/tahun (4 Perawat). Hal ini menunjukkan bahwa kegiatan pelayanan unit gawat darurat membutuhkan waktu 1/702-708 dari hari anamnesis pasien, pemeriksaan fisik, pemeriksaan tekanan darah membutuhkan waktu 1/16848 dari hari kerja tersedia dalam 1 tahun. Sedangkan perhitungan beban kerja pada tenaga farmasi yang paling tinggi adalah pelayanan informasi obat pasien yakni sebesar 5712 menit/tahun/ petugas, hal ini pelayanan informasi obat 
pasien membutuhkan waktu 1/5712 dari hari kerja tersedia dalam 1 tahun. Sedangkan kegiatan yang memiliki standar beban kerja yang rendah adalah pembuatan laporan alur masuk obat dan pelaporan pemeriksaan laboratorium sebesar 237 menit/tahun/ petugas, hal ini menunjukkan pembuatan laporan alur masuk obat dan pelaporan pemeriksaan laboratorium membutuhkan waktu 1/237 dari hari kerja tersedia dalam 1 tahun. Jadi, bila rata-rata waktu perkegiatan kecil maka akan menghasilkan suatu pekerjaan yang banyak dan sebaliknya jika ratarata waktu perkegiatan yang semakin besar maka menghasilkan suatu pekerjaan yang sedikit.

\section{Standar Kelonggaran}

Hasil penelitian menunjukkan bahwa tenaga perawat (tabel 2) pada poliklinik UIN Alauddin Makassar memiliki standar kelonggaran yang berbeda pada setiap petugas/Responden , yaitu terdiri dari $\mathrm{R} 1=$ $0.0142, \mathrm{R} 2=0.0141, \mathrm{R} 3=0.0142$, dan $\mathrm{R} 4=$ 0.0513 (jumlah standar kelonggaran tenaga keperawatan $=0,0938), \quad$ SDM atau dengan kata lain petugas tersebut membutuhkan waktu untuk faktor kelonggaran sebesar $1,41 \%$ sampai dengan $5,1 \%$ dari total waktu yang tersedia. Standar kelonggaran paling banyak membutuhkan waktu adalah merekap pemeriksaan kesehatan mahasiswa baru dengan standar 0.037 SDM atau 3.7\% dari total waktu kerja yang tersedia. Sedangkan tenaga farmasi (tabel 3) pada poliklinik UIN Alauddin Makassar memiliki standar kelonggaran yang hamper sama pada petugas/responden , yaitu 0,086dan 0,083 (jumlah standar kelonggaran tenaga farmasi $=0,1697$ ) atau dengan kata lain petugas tersebut membutuhkan waktu untuk faktor kelonggaran sebesar $16,9 \%$ dari total waktu yang tersedia.

\section{Kebutuhan Tenaga SDM}

Berdasarkan perhitungan kebutuhan tenaga perawat dengan metode Workload Indicator Staffing Need, maka diperoleh tenaga perawat sebanyak 0,695 atau jika dibulatkan menjadi 1 SDM. Sedangkan jumlah tenaga perawat yang ada di poliklinik UIN Alauddin Makassar adalah 4 orang (table 4). Sedangkan jumlah kebutuhan tenaga farmasi yang yang ideal adalah sebesar 3,38 atau 4 SDM, . Sedangkan jumlah tenaga farmasi yang ada di poliklinik UIN Alauddin Makassar adalah 2 orang (tabel 5).

\section{PEMBAHASAN}

Perhitungan standar beban kerja kegiatan paramedis pada polklinik UIN Alauddin Makassar yang dilakukan didasarkan pada pengamatan yang dilakukan oleh peneliti. Standar beban kerja tenaga paramedis diperoleh melalui perhitungan per- 
bandingan waktu rata-rata yang dibutuhkan perkegiatan pokok dengan waktu kerja tersedia yang dimiliki selama kurun waktu satu tahun. Data yang didapat ini kemudian diolah untuk menghasilkan analisa mengenai beban kerja tertinggi dan jenis perkerjaan yang membutuhkan waktu terbanyak.

Menurut Fitriani et al.(2016) Beban kerja yang tidak sesuai jika dilihat dari aspek kuantitas kegiatan yang dilakukan oleh tenaga medis baik dokter spesialis maupun tenaga medis lainnya dapat menimbulkan stress dan berakibat pada kualitas pelayanan yang diberikan pada pasien sebagai penerima pelayanan kesehatan. Sejalan dengan Kurniawan (2016) yang menyimpulkan bahwa beban kerja memiliki dampak yang signifikan terhadap kinerja petugas. Sejalan dengan penelitian tyas (2009), yang menyatakan beban kerja berlebihan (work-overload) dengan stres kerja pada Bidan Delima di Wilayah Surabaya, artinya semakin tinggi beban kerja berlebihan (work-overload) semakin tinggi pula stres kerjanya. sehingga ada hubungan antara beban kerja (work-overload) dengan stres kerja pada Bidan Delima di Wilayah Surabaya.

Penyusunan standar kelonggaran pada analisis sumber daya manusia bertujuan untuk memperoleh faktor kelonggaran setiap kategori sumber daya manusia yang meliputi jenis dan kebutuhan waktu untuk menyelesaikan suatu kegiatan yang tidak terkait langsung atau dipengaruhi tinggi rendahnya kualitas atau jumlah kegiatan pokok/pelayanan.

Standar kelonggaran paling banyak membutuhkan waktu adalah merekapitulasi pemeriksaan kesehatan mahasiswa baru dengan standar 0.042 SDM atau 4.2\% dari total waktu kerja yang tersedia. Standar kelonggaran ini adaladah waktu kerja yang dihabiskan untuk melaksanakan tugas tambahan yang tidak berkaitan langsung dengan tugas pokok. Adanya faktor kelonggaran ini akan mengurangi waktu kerja tersedia yang sebenarnya dapat menambah kebutuhan tenaga.

Metode perhitungan kebutuhan SDM berdasarkan beban kerja (WISN) adalah indikator yang menunjukkan besarnya kebutuhan tenaga pada sarana kesehatan berdasarkan beban kerja, sehingga alokasi/ relokasi tenaga akan lebih mudah dan rasional. Kelebihan metode ini mudah dioperasikan, mudah digunakan, secara teknis mudah diterapkan, komprehensif dan realistis.

Pemenuhan tenaga paramedis dengan menggunakan metode WISN bukanlah menjadi metode yang mutlak dilakukan oleh para perencana kebutuhan SDM, na- 
mun sebagai salah satu metode dari pemerintah untuk memudahkan dalam pemenuhan dan distribusi dari tenaga kesehatan. Metode WISN dapat digunakan di semua unit kerja, perhitungannya lebih riil karena berdasarkan beban pekerjaan yang nyata. Namun ada kelemahan dari metode ini antara lain membutuhkan standar pelayanan untuk masing - masing kategori tenaga, membutuhkan standar waktu untuk melaksanakan tugas dan membutuhkan data (daftar hadir, jumlah kunjungan, kuantitas kegiatan, BOR, LOS) pada tahun-tahun sebelumnya sehingga sulit bila akan menghitung kebutuhan tenaga pada unit baru.

\section{KESIMPULAN}

Hasil analisis kebutuhan tenaga paramedis berdasarkan beban kerja petugas dengan menggunakan metode WISN pada Poliklinik Ass-Syifah UIN Alauddin Makassardiperoleh tenaga perawat sebanyak 0,695 SDM atau jika dibulatkan menjadi 1 SDM. Jumlah tenaga perawat yang ada di poliklinik UIN Alauddin Makassar adalah 4 orang. Sedangkan jumlah kebutuhan tenaga farmasi yang ideal adalah sebesar 3,38 SDM atau 4 SDM. Jumlahtenaga farmasi yang ada di poliklinik UIN Alauddin Makassar adalah 2 orang. Perawat yang ada saat ini dapat diperbantukan pada unit lainnya sehingga tidak terdapat overload beban kerja pada tenaga paramedis lainnya.

\section{SARAN}

Kami menyarankan kepada pimpinan institusi UIN Alauddin Makassar agar dapat memenuhi jumlah tenaga SDM sesuai dengan proporsi dari analisis kebutuhan SDM. Penggunaan metode WISN ini untuk memudahkan dalam pemenuhan dan distribusi dari tenaga kesehatan terutama di poliklinik. Dengan adanya hasil penelitian ini peneliti berharap agar jumlah kebutuhan SDM khususnya di poliklinik dapat di evaluasi.

\section{DAFTAR PUSTAKA}

Arikunto, Suharsimi. 2005. Manajemen Penelitian. Edisi Revisi, Cet Ketujuh; Jakarta: PT. Rineka Cipta.

A.a. Ngr. Gd. Dharmayuda. 2015. Analisis Beban Kerja Dokter Umum Menggunakan Metode Workload Indicators Of Staffing Need (Wisn) Di Pusksemas Se-Kota Denpasar. Tesis. Denpasar : Universitas Udayana.

Badan Perencanaan Pembangunan Nasional. 2005. Laporan Kajian Kebijakan Perencanaan Tenaga Kesehatan. Deputi Bidang Sumber Daya Manusia dan Kebudayaan. Jakarta Depkes RI. 2009. Perlengkapan Untuk Pengembangan Indikator Beban Kerja Petugas (Wisn) Untuk Memperbaiki Perencanaan Dan Manajemen Tenaga Kerja Kesehatan Dalam Sistem Kesehatan Yang Di Desentralisasi. Jakarta : PPSDM Kemenkes RI.

Departemen Kesehatan RI dan GTZ. 2009. Perlengkapan Kerja WISN : Perlengkapan Untuk Pengembangan Indikator Beban Kerja Petugas (WISN) Untuk Memperbaiki Perencanaan Dan Manajemen Tenaga Kerja Kesehatatan Dalam Sistem Kesehatan Yang Di 
Desentralisasi. BPPSDM Kesehatan. Jakarta.

Doulati, S.P. et al. 2013. The Assessment of Needed Workload for Manpower Approximation in Health Houses in Iran $=s$ Villages. European Journal of Scientific Research 114(1): 139-148.

Eska Distia dan Widodo Jatim Pudjirahardjo.2015. Weakness Of Workload Indicators Staffing Need In Calculating The Number Of Health Workers In Public Health Center. Jurnal Administrasi Kesehatan Indonesia Volume 3 Nomor 1 Januari-Juni 2015. Surabaya ; Universitas Airlangga.

Hagopian, A. et al. 2012. Applying WHO's -Workforce Indicators of Staffing Need $\|$ (WISN) Method to Calculate the Health Worker Requirements for India's Maternal and Child Health Service Guarantees in Orissa State. Health Policy and Planning 27(1): 11 -18 .

Kementerian Kesehatan RI. 2013. Pedoman Pelaksanaan Analisis Beban Kerja DI Lingkungan Kementerian Kesehatan. Sekretariat Jenderal Kementerian Kesehatan. Jakarta. Keputusan Menteri Kesehatan Republik Indonesia Nomor : 81/Menkes/SK/ I/2004. Pedoman Penyusunan Perencanaan Sdm Kesehatan Di Tingkat Propinsi, Kab/Kota Serta Rumah Sakit. Departemen Kesehatan RI. Ja- karta.

Mugisha, J.F, dan G. Namaganda. 2008. Using The Workload Indicators of Staffing Need (WISN) Methodology to Assess Work Pressure Among the Nursing Staff of Lacor Hospital. Vol 6; Edisi 1; Hal 1-15. HealthPolicy and Development Journal.

Mcquide, P.A. dan Forster, N. 2013. Applying The Workload Indicators of Staffing Need ( WISN ) Method in Namibia : Challenges and Implications for Human Resources for Health Policy. Human resources for health 11 .

Notoatmodjo. S. 2002. Metodologi Penelitian Kesehatan. Edisi Revisi, Jakarta : PT Rineka Cipta.

Nuryati. 2014. Perencanaan Kebutuhan Tenaga Rekam Medis Dengan Metode Workload Indicators Of Staffing Need (Wisn) Di Puskesmas Gondokusuman Ii Kota Yogyakarta. Yogyakarta : Sekolah Vokasi UGM.

Undang-Undang Republik Indonesia Nomor 36 Tahun 2014. Tentang TenagaKesehatan.www.hukumonline.com

Wahjoe Harijanto.2014. Penentuan Kebutuhan Tenaga di RS HVA Toeloengredjo dengan Metode Workload Indicators of Staffing Need (WISN) untuk Efisiensi Sumber Daya Manusia. Jurnal Kedokteran Universitas Brawijaya 